\title{
Crítica, genealogía y política: una conversación con Santiago Castro-Gómez*
}

\author{
Joel Rojas, Rosa María Mantilla, Bernardo Villegas
}

Primera pregunta: Profesor, usted ha señalado que su trabajo filosófico se inscribe en la tradición moderna de la crítica. Bajo esta perspectiva, y tomando en cuenta las ideas presentadas hace varios años en Crítica de la razón latinoamericana, ¿cuál es su propuesta actual sobre el papel de la filosofía en América Latina en respuesta a una 'latinoamericanización de la filosofía'?

Es verdad que desde mi primer libro, Crítica de la razón latinoamericana, me he posicionado en contra del proyecto de construir una filosofía 'auténtica' de América Latina, entendida como un pensamiento anclado en nuestra 'identidad', armado con unas categorías propias, completamente distintas a las desarrolladas por la tradición de la filosofía occidental. La razón que me llevó a criticar este proyecto fue su carácter identitario y colonial. Los defensores del proyecto latinoamericanista decían que el significante 'Latinoamérica' hace referencia a una 'cultura', a una 'identidad' que se halla en la 'exterioridad' de la modernidad occidental (vista ésta como una totalidad dominadora). Crítica de la razón latinoamericana argumenta por el contrario, que 'Latinoamérica' no hace referencia a una 'cosa en sî' (no es un lugar geográfico y mucho menos

\footnotetext{
* Esta entrevista se realizó el 13 de julio en la Facultad Latinoamericana de Ciencias Sociales, Sede Ecuador, con motivo del seminario 'Marx y la política' dictado por el profesor Castro-Gómez.
} 
una 'cultura'), sino que es un discurso surgido hacia finales del siglo XIX que se vinculó desde entonces a diferentes 'regímenes de verdad'. El libro pretende hacer una arqueología de ese discurso latinoamericanista y mostrar el tipo de relaciones de poder con los que se vincula. En el libro se impugna la ilusión de una supuesta 'razón latinoamericana' que se ubica por fuera de la modernidad y abre la puerta a una consideración mucho más compleja del modo en que la modernidad y la colonialidad se relacionan históricamente en nuestro medio. Con todo, y a pesar de sus graves limitaciones, hay algo en ese viejo proyecto latinoamericanista que merece hoy día ser rescatado: la necesidad de ir más allá del proyecto europeo de la modernidad (ique no es lo mismo que 'desprenderse' de la modernidad!) para apropiarlo críticamente desde sus márgenes. Pero ir 'más allá' de ese proyecto europeo quiere decir hacerlo nuestro, canibalizarlo y atravesarlo.

A pesar de que han pasado ya casi veinticinco años desde que escribí Crítica de la razón latinoamericana, sigo creyendo que no necesitamos 'latinoamericanizar' la filosofía —sus contenidos, temas, métodos y categorías de análisis - para tener como resultado una filosofía descolonizada. Sigo creyendo que el papel de la crítica filosófica en nuestro medio es señalar los obstáculos que nos impiden apropiarnos del legado emancipatorio de la modernidad. Obstáculos tales como el latinoamericanismo del siglo pasado y el abyayalismo del siglo presente, que insisten en la necesidad de recuperar una 'exterioridad' (epistémica, política, religiosa, etc.) frente a la modernidad como marca de un proyecto de 'liberación'. En la crítica de este antimodernismo radical, que considero conservador y reaccionario, he venido trabajando durante todos estos años. Practicar la filosofía en América Latina, con la conciencia crítica de estar pensando desde el cruce entre la modernidad y la colonialidad, significa que no debemos temer apropiarnos del legado europeo. El hecho de hablar 
y pensar desde lugares epistémicos donde la modernidad es colonial y la colonialidad es moderna (como es el caso por ejemplo, de Colombia) nos permite interrogar esa tradición europea con preguntas diferentes, lo cual abre la puerta para hacer nuestra esa historia de la modernidad, avanzando de forma simultánea más allá de ella. Por eso creo que el reto que tenemos adelante no es latinoamericanizar la filosofía sino transmodernizarla, esto es, abrirse hacia un diálogo crítico desde América Latina con las tradiciones de la filosofía moderna europea. La fagocitación de ese canon moderno en base a interrogantes surgidos en este lugar del mundo es ya la marca de una filosofía descolonizada.

Segunda pregunta: En La Hybris del Punto Cero, usted retomó el concepto colonialidad del poder para abordar la dimensión epistémica de las relaciones coloniales de poder en la Nueva Granada y, en ese sentido, analizó el funcionamiento del discurso moderno ilustrado durante la colonia y desde qué lugares fue leído. Sin embargo, usted ha cuestionado ciertas posiciones de los miembros del Grupo Modernidad/Colonialidad que apuestan a un particularismo o un esencialismo. ¿Qué limitaciones percibe en el pensamiento decolonial y qué implicaciones tiene para América Latina?

He participado de las actividades de esta red y utilizado varios de los conceptos generados allí. Pero en la respuesta a la pregunta anterior, quedó claro que mi aproximación al tema de las herencias coloniales es algo diferente a la de otros autores que también participaron en la misma. Sin necesidad de mencionar nombres concretos, digamos que algunos autores defienden una visión 'totalizante' de la modernidad. Identifican la modernidad en su conjunto con el genocidio, el epistemicidio, el colonialismo, el ecocidio y la destrucción sistemática de las tradiciones culturales de los pueblos. Al 
mismo tiempo identifican (como si fuera la misma cosa) la modernidad con el capitalismo. Como contraparte a esta visión plantean la necesidad de recuperar las 'epistemes-otras' de los pueblos subalternos como alternativa real a la modernidad. Por mi parte, he preferido no identificar la modernidad con el colonialismo ni con el capitalismo, aún sabiendo que ella tiene una dimensión colonial y capitalista. Pienso que la modernidad también arrastra consigo unas tradiciones críticas y emancipatorias que no podemos echar en saco roto. Como bien lo vieron Hegel y Marx, es necesario pensar la modernidad 'dialécticamente', tomando en cuenta no sólo sus elementos patológicos y destructores, sino también sus potencialidades emancipatorias. Coincido con los colegas de la red en que la modernidad es un serio problema en América Latina (puesto que viene ligada al colonialismo y al capitalismo), pero también entiendo que es parte de la solución. Por eso me parece un gravísimo error renunciar al universalismo político de la modernidad para favorecer, en su lugar, al particularismo de las comunidades subalternas. Estos proyectos comunitarios son desde luego legítimos, pero tendrían que encontrar su lugar en un proyecto hegemónico válido para todos y no solo para los miembros de una comunidad particular. Es por eso que prefiero hablar de 'emancipación' y no de 'liberación'. No se trata solo de pensar en la liberación comunitaria de aquellos que fueron víctimas de las patologías modernas, sino en una sociedad emancipada. No la liberación de los subalternos, sino la emancipación de dominadores y dominados. Esta, me parece, continúa siendo la labor de una teoría crítica de la sociedad, y en este punto me mantengo fiel a la tradición de la Escuela de Frankfurt.

Tercera pregunta: Tal como usted lo señaló en su libro Historia de la gubernamentalidad I, el paso del modelo bélico al modelo gubernamental 
constituyó un giro importante en la obra foucaultiana. De allí se ha desprendido toda una corriente de investigación orientada a expandir este análisis a otros casos históricos. ¿Qué elementos se deberían tomar en cuenta para comprender las gubernamentalidades en América Latina?

Evidentemente, en el libro que ustedes mencionan, traté de señalar la potencia conceptual y heurística del concepto 'gubernamentalidad' en la obra tardía de Michel Foucault. Reconozco la importancia que nos ofrece esta categoría para entender ciertas situaciones históricas en América Latina, y particularmente la he utilizado para entender el funcionamiento de ciertos dispositivos de poder en la historia moderno-colonial de mi país. Pero también he señalado los límites de esta categoría, porque con el tiempo me he venido convenciendo de que una cosa es pensar el poder y otra cosa distinta es pensar la política. Es verdad que toda política conlleva el ejercicio de poder, pero también es cierto que no todo ejercicio de poder es inmediatamente 'político', tal como pensaba Foucault. Lo cual significa que no es correcto reducir el ejercicio de la política a un asunto de 'gubernamentalidad'. El concepto sirve mucho para un análisis histórico que analice la emergencia de dispositivos de poder, el modo cómo han operado estos dispositivos, cómo han servido para subalternizar otros saberes, otras formas de vida, etc. Pero solo con el concepto de gubernamentalidad no nos alcanza para pensar la política como tal.

Cuarta pregunta: Debido al surgimiento de algunos regímenes progresistas en América Latina (Ecuador, Venezuela, Bolivia), varios autores han hablado del 'retorno del Estado' como un nuevo tipo de régimen, pues se asume que el debate sobre neoliberalismo/progresismo radica más en la estructura institucional del Estado que en la racionalidad de gobierno detrás 
de ella. ¿Cómo diagnosticarías esta situación desde una óptica foucaultiana? ¿Es posible hablar de posneoliberalismo?

No, yo creo que no es posible hablar en estas circunstancias de un 'posneoliberalismo' porque eso supondría que la izquierda hubiese alcanzado la hegemonía económica, pero esto no ocurrió. Los gobiernos progresistas gobernaron en realidad a contracorriente, es decir que, como diría Gramsci, gobernaron pero no dirigieron. Gobernaron políticamente los Estados, pero no alcanzaron la hegemonía económica, que siempre la tuvo el neoliberalismo. Lo que hicieron estos gobiernos fue tratar de recuperar el Estado, atacar desde ahí las desigualdades generadas por la economía neoliberal, pero no lograron llegar a un posneoliberalismo. Siempre estuvieron caminando con el viento en contra. Por eso se vieron obligados a hacer importantes concesiones al desarrollismo, al extractivismo, por la que fueron duramente criticados desde los movimientos sociales. Es en base a estas críticas que muchos intelectuales de izquierdas hablan de un 'fracaso' de esos gobiernos progresistas. Yo me pregunto: ¿fracaso en relación a qué? Tal vez en relación a ciertos ideales puristas de la veteroizquierda latinoamericana. Pues lo cierto es que, a pesar de no haber conseguido la tan ansiada hegemonía económica, con todas las concesiones políticas que este hecho supuso, e incluso a pesar de ciertas derivas autoritarias, los gobiernos progresistas (unos más que otros) consiguieron evidentes avances sociales en la región. Debemos entender que la izquierda no está ahí para hacer milagros. Una cosa es estar en la oposición y otra muy distinta es gobernar. Porque cuando gobiernas debes aprender a moverte en el tablero político conforme sea la relación de fuerzas realmente existente. Debes comprender cuáles son las condiciones reales del antagonismo. Y en el caso de la llamada 'década ganada', esa relación de fuerzas jamás favoreció la 
posibilidad de una hegemonía económica por parte de la izquierda en la región. Miren no más el caso de Venezuela.

Quinta pregunta: El filósofo Slavoj Žižek sostiene que el posmodernismo surgió en Mayo del 68 y posteriormente tuvo una marcada influencia en la izquierda, en el feminismo y en tendencias académicas como el posestructuralismo y los estudios culturales. La crítica principal de este filósofo esloveno a la izquierda mundial apunta a lo que en su libro Revoluciones sin sujeto (2015) usted denomina el 'historicismo posmoderno'. ¿Qué limitaciones encuentra en esta apreciación de Žižek sobre la izquierda posmoderna?

En mi libro Revoluciones sin sujeto acepto en buena parte las críticas de Žižek al historicismo posmoderno. Žižek se da cuenta perfectamente que muchas de las apuestas de un cierto sector de la izquierda en el mundo, hoy en día, son apuestas particularistas. Se lucha en contra de las exclusiones en términos de género, raza y orientación sexual. Se lucha también por la preservación del entorno ecológico. Pero lo que le parece a Žižek es que estas distintas luchas no están articuladas entre sí; más bien pareciera que se trata de reivindicaciones particulares. Yo estoy de acuerdo en principio con esta crítica, pues como dije antes, me parece que las luchas emancipatorias deben levantar una pretensión de universalidad política. En mi libro he argumentado ampliamente sobre la necesidad de que la política sea entendida como la construcción de una voluntad común, en la que los intereses de un sector de la sociedad puedan ser presentados hegemónicamente como válidos para todos. La política consiste, precisamente, en la construcción de esos intereses generales, de esa voluntad colectiva, de ese 'pueblo'. Éste no preexiste a las luchas políticas, no está dado jamás de antemano, como en algún momento lo planteó Dussel. Aquí me parece que el joven Žižek 
tiene razón. Sin embargo, el Žižek más tardío ha derivado en una ceguera frente a los logros de estas luchas particulares. Es verdad que el feminismo es criticable si tan solo centra su interés en la liberación de las mujeres (o de aquellas personas que se identifican como mujeres) con exclusión de todos los demás. Pero si uno mira con cuidado, las luchas feministas han logrado transformar el sentido común que comparten hombres y mujeres, hasta el punto en que todos los días se habla hoy de agresiones sexistas, violencia intrafamiliar o exclusiones de género en casi todos los noticieros de todo el mundo. Esto no quiere decir que ahora haya más violencia de género que antes. Lo que quiere decir es que la lucha feminista ha logrado visibilizar una serie de violencias y desigualdades que antes no eran visibles por la predominancia casi absoluta del machismo en el sentido común. Entonces, a diferencia de lo que afirma Žižek, las luchas feministas sí han logrado modificar el sentido común en un sentido progresista. Cosa que, en realidad, no ha logrado todavía la izquierda 'dura' que defiende el esloveno, centrada en el proyecto de ganar el control de los aparatos de Estado y gobernar. Del feminismo la izquierda latinoamericana debe aprender que sin una modificación del sentido común, no conseguirá transformaciones profundas aunque tenga la hegemonía de las instituciones políticas. ¿Por qué? Porque las desigualdades contra las que combate la izquierda (de género, de raza, de clase, de orientación sexual) se hallan firmemente ancladas en formas de valoración asentadas en el sentido común, en la Lebenswelt. Sin una modificación de ese ethos, de esas formas de valoración históricamente heredadas, marcadas en buena parte por el colonialismo, no será mucho lo que pueda hacer la izquierda en el poder. No hay mucha diferencia entre un macho de izquierdas y un macho de derechas, entre un racista conservador y otro progresista, o entre un político que roba con la mano derecha y otro que roba con la izquierda. No se lograrán cambios profundos mientras 
la hegemonía se limite simplemente a tomar los aparatos del Estado y gobernar. No basta solo con gobernar el Estado, es necesario también modificar el sentido común que comparten dominadores y dominados. No se trata de cambiar solo la Constitución, las leyes y las normas sociales, sino también las formas de sentir, de ver, de experimentar el mundo. El proyecto político emancipatorio de la izquierda debe ser también un proyecto ético y estético. Tal vez en esto radicó la gran limitación del ciclo progresista latinoamericano de comienzos del siglo XXI.

Sexta pregunta: Dentro del plano de la filosofía política, Žižek califica negativamente a la democracia como pospolítica, es decir, como un gobierno de tecnócratas. Contrariamente, usted, retomando la filosofía política de Ernesto Laclau y Enrique Dussel, apuesta por una política dentro del horizonte democrático. ¿Podría explicarnos cuáles son actualmente las potencialidades emancipatorias de la democracia?

Aunque Žižek tiene razón en sus críticas a la democracia liberal parlamentaria representativa, me parece que esta no agota el concepto mismo de democracia. Yo creo que hay una tradición de democracia republicana que Žižek no considera en sus trabajos. Él piensa que toda democracia es liberal. En esto está vinculado en la tradición marxista que dice que todo lo que viene de la revolución francesa es pensamiento burgués y que por tanto las formas que adquiere el Estado democrático después de la revolución francesa, son una simple expresión de los intereses de la burguesía. Por eso Žižek identifica toda democracia per se con la democracia liberal. Ahora bien, lo que argumento en Revoluciones sin sujeto es que quien habla de democracia no necesariamente habla de representación en el parlamento ni de la defensa de los derechos individuales. Hay una tradición republicana que nace antes del liberalismo del siglo XVIII para la que la libertad no 
significa solo la libertad del individuo, sino que significa la 'no dominación'. La libertad significa el no estar a merced o al servicio de alguien más. Y la igualdad significa que todos los ciudadanos deben estár en la capacidad de poder acceder a los recursos materiales y simbólicos que les permitan esa condición de no servidumbre. Como ven, el republicanismo maneja un concepto de igualdad y libertad que desborda con mucho los conceptos liberales, pero de todo esto no se ha enterado Žižek.

Séptima pregunta: A lo largo del desarrollo de su trabajo teórico iniciado por el canónico libro Crítica de la razón latinoamericana, pasando hasta sus trabajos genealógicos sobre los dispositivos de poder en Colombia, usted actualmente se propone retornar al pensamiento político de Marx con el objetivo de repensar una política emancipadora en América Latina. ¿Por qué es importante este retorno de la acción política a partir de los escritos del 'joven Marx' (1843-1848)?

Bueno, eso tiene que ver precisamente con el problema del republicanismo. Por lo general se ha dicho que el joven Marx, vale decir, el Marx anterior al descubrimiento del materialismo histórico, era un Marx 'liberal'. Un Marx que todavía no era Marx. Un Marx que se movía todavía en la órbita de la ilustración francesa, de Hegel y de Feuerbach. Pues bien, lo que me propongo es mostrar que ese joven Marx no era tanto liberal sino republicano. Y que en los escritos anteriores a La ideología alemana pueden rastrearse las huellas de lo que podríamos llamar un republicanismo plebeyo. Todo esto exige desde luego replantear la relación entre Marx y la izquierda hegeliana. Lo que quiero mostrar es que esos vínculos eran mucho más estrechos de lo que el propio Marx estaba dispuesto a reconocer. Tal vez él mismo era miembro de esa 'sagrada familia' contra la que luchó desesperadamente por separarse. Me gustaría examinar detenidamente 
algunos textos de Bruno Bauer, Arnold Ruge, Moses Hess y Ludwig Feuerbach para detectar en ellos ese 'momento republicano' que el propio Marx compartió y no abandonó jamás del todo. Pero todo esto es aún work in progress. Ya veremos lo que sale.

Octava pregunta: ¿Cómo se vincula usted con ese proyecto de las 'epistemologías del Sur' que ha defendido últimamente el sociólogo portugués Boaventura de Sousa Santos? ¿Qué piensa de esto?

Concuerdo con Boaventura en que el pensamiento crítico (no sólo el latinoamericano) debería tomarse muy en serio la emergencia de los pueblos originarios de las Américas ocurrida desde los años noventa del siglo pasado. Esto conlleva un desafío no solo político sino epistémico, porque los indígenas han puesto sobre la mesa de discusión algunos temas que desbordan los parámetros del pensamiento moderno occidental. Me refiero a asuntos como el 'buen vivir' de los pueblos andinos y el 'buen gobierno' de los zapatistas, que suponen un relacionamiento distinto con la naturaleza y con las comunidades. Una ontología diferente. Ahora bien, dicho esto, 'tomarse en serio' este desafío epistémico no significa necesariamente abandonar del todo los elementos críticos de la modernidad. Esto ya lo dije antes. Supone, más bien, ampliar el horizonte de esos elementos, llevarlos hacia otros escenarios. Introducir por ejemplo en el vocabulario de la filosofía política nociones tales como interculturalidad, plurinacionalidad, ecología de los saberes, etc. Pero insisto, nada de esto significa que debamos abandonar las tradiciones críticas del pensamiento moderno y creo que Boaventura de Sousa Santos no propone algo semejante. Entiendo su programa de las 'epistemologías del Sur' como una ampliación significativa de la teoría social moderna y no como su negación. Es una invitación a descolonizar el pensamiento, pero sin que ello signifique un 'desprendimiento' de la 
modernidad, como algunos teóricos equivocadamente proponen. Una cosa es combatir el eurocentrismo, y en esto coincidimos con Boaventura y con los colegas de la red modernidad/colonialidad, pero otra cosa muy distinta es decir que el pensamiento moderno es producto de una historia local específica ('Europa') y que por tanto no puede ser aplicado a otras historias locales diferentes. Este es justo el problema del 'historicismo posmoderno' que con toda razón critica Žižek. Decir que los derechos humanos, las libertades ciudadanas, la ciencia moderna y la crítica racional son productos 'europeos' que no tienen valor fuera de su contexto cultural específico (y que aplicarlos ahí es una expresión de 'colonialismo') es en realidad un argumento reaccionario. El proyecto de las 'epistemologías del Sur' no debe ser confundido entonces con un comunitarismo anti-moderno, ni con un subalternismo anti-sistémico. 